\title{
Simulated Microgravity Reduces Proliferation and Reorganizes the Cytoskeleton of Human Umbilical Cord Mesenchymal Stem Cells
}

\author{
Ho Nguyen QUYNH CHI ${ }^{1,2^{*}}$, Hoang NGHIA SON ${ }^{1,2^{*}}$, Doan CHINH CHUNG ${ }^{1,2}$, Le Dinh \\ HUAN $^{4}$, Tran HONG DIEM ${ }^{3}$, Le Thanh LONG ${ }^{1,2}$ \\ * These authors contributed equally to this work.
}

${ }^{1}$ Animal Biotechnology Department, Institute of Tropical Biology, Vietnam Academy of Science and Technology, Ho Chi Minh City, Vietnam, ${ }^{2}$ Biotechnology Department, Graduate University of Science and Technology, Vietnam Academy of Science and Technology, Ha Noi, Vietnam, ${ }^{3}$ Department of Internal Medicine - Cardiology, UT Southwestern Medical Center, Dallas, TX, USA, ${ }^{4}$ BD Biosciences Vietnam, Ho Chi Minh City, Vietnam

Received March 27, 2020

Accepted August 4, 2020

Epub Ahead of Print September 9, 2020

\begin{abstract}
Summary
The cytoskeleton plays a key role in cellular proliferation, cellshape maintenance and internal cellular organization. Cells are highly sensitive to changes in microgravity, which can induce alterations in the distribution of the cytoskeletal and cell proliferation. This study aimed to assess the effects of simulated microgravity (SMG) on the proliferation and expression of major cell cycle-related regulators and cytoskeletal proteins in human umbilical cord mesenchymal stem cells (hucMSCs). A WST-1 assay showed that the proliferation of SMG-exposed hucMSCS was lower than a control group. Furthermore, flow cytometry analysis demonstrated that the percentage of SMG-exposed hucMSCs in the G0/G1 phase was higher than the control group. A western blot analysis revealed there was a downregulation of cyclin A1 and A2 expression in SMG-exposed hucMSCs as well. The expression of cyclin-dependent kinase 4 (cdk4) and 6 (cdk6) were also observed to be reduced in the SMG-exposed hucMSCs. The total nuclear intensity of SMG-exposed hucMSCs was also lower than the control group. However, there were no differences in the nuclear area or nuclear-shape value of hucMSCs from the SMG and control groups. A western blot and quantitative RT-PCR analysis showed that SMG-exposed hucMSCs experienced a downregulation of $\beta$-actin and a-tubulin compared to the control group. SMG generated the reorganization of microtubules and microfilaments in hucMSCs. Our study supports the idea that the downregulation of major cell cycle-related
\end{abstract}

proteins and cytoskeletal proteins results in the remodeling of the cytoskeleton and the proliferation of hucMSCs.

\section{Key words}

Cell proliferation - Cytoskeleton - Human umbilical cord mesenchymal stem cells $\bullet$ Simulated microgravity

\section{Corresponding author}

L. T. Long, Animal Biotechnology Department, Institute of Tropical Biology, 9/621 Hanoi Highway, Linh Trung Ward, Thu Duc District, Ho Chi Minh City 700000, Vietnam. E-mail: longlt@itb.ac.vn

\section{Introduction}

SMG can be generated by clinorotators, rotating wall vessels, and 2D or 3D clinostats (Chen et al. 2016, Mao et al. 2016, Devarasetty et al. 2017, Cazzaniga et al. 2016). They have been used to study the effects of SMG on the proliferation, structure and function of a variety of mammalian cell lines, especially stem cells (Imura et al. 2019). SMG has induced cytoskeletal rearrangements of endothelial cells by modifying gelsolin and $\alpha$-tubulin expression (Griffoni et al. 2011), and the C2C12 mouse myoblast has, under SMG, demonstrated decreased proliferation and downregulation of transient receptor potential canonical type 1 and insulin-like growth factor 1

PHYSIOLOGICAL RESEARCH • ISSN 1802-9973 (online) 
isoforms (Benavides et al. 2013, Benavides et al. 2014). Increases in osteoclastogenesis has also been reported in mouse bone marrow cells under SMG conditions using autophagy markers (Sambandam et al. 2014). Changes in the immune system have also been described under SMG, with T-lymphocyte signal transduction modified by SMG, leading to a weaken immune system (Rea et al. 2016). Furthermore, SMG has been shown to correlate with immune depression by altering the expression of arginase and inflammatory cytokines in macrophages (Wang et al. 2015).

Human umbilical cord mesenchymal stem cells (hucMSCs) have recently emerged as a novel resource in regenerative medicine due to their therapeutic and biotechnological potentials and need for minimal manipulation (Weiss and Troyer 2006, Marino et al. 2019). Mesenchymal stem cells (MSCs) can be isolated from different tissues (Cruciani et al. 2019, Kladnická et al. 2019) and are able to differentiate into various cell types (Trávníčková and Bačáková 2018). It has been observed that an increase in F-actin reorganization and cell stiffness inhibits cell migration in rat MSCs (Mao et al. 2016), and potential differentiation in rat bone MSCs depends on changes in gravity, e.g. hypergravity can increase osteogenesis and differentiation into cardiomyocytes, while SMG promotes rat MSC differentiation into adipocytes (Huang et al. 2009). SMG has also been reported to stimulate osteogenic differentiation of human bone MSCs (Cazzaniga et al. 2016). Another report has shown that the proliferation and osteogenic differentiation of rat bone MSCs could be inhibited by SMG (Chen et al. 2016). The inhibition of proliferation was also demonstrated in human hematopoietic progenitor cells, bone marrow MSCs, and mouse MSCs (Plett et al. 2004, Yan et al. 2015, Touchstone et al. 2019). However, the mechanisms behind the reduction of cell proliferation remains unclear. Therefore, in this study, hucMSCs were used to assess the effects of SMG on the expression of major cell cyclerelated regulators and cytoskeletal proteins that control proliferation.

\section{Materials and Methods}

\section{Thawing and culturing of hucMSCs}

Passage 1 hucMSCs were supplied by Dr. Doan (Doan et al. 2013, Doan et al. 2014). The cryotube containing hucMSCs was removed from liquid nitrogen and incubated at $37^{\circ} \mathrm{C}$ for $30 \mathrm{~s}$. The hucMSCs were then resuspended and transferred to a $15 \mathrm{ml}$ tube containing $4 \mathrm{ml}$ DMEM/Ham's F-12 (DMEM-12-A; Capricorn Scientific, Ebsdorfergrund, Germany) supplemented with $15 \%$ fetal bovine serum (FBS-HI-22B, Capricorn Scientific) and $1 \%$ penicillin/streptomycin (15140-122; Thermo Fisher Scientific ${ }^{\mathrm{TM}}$ Gibco, Waltham, MA, USA). The cell pellets were then resuspended and transferred to a T-25 flask with $4 \mathrm{ml}$ of culture medium and cultured at $37{ }^{\circ} \mathrm{C}$ with $5 \% \mathrm{CO}_{2}$. The evaluation of hucMSC markers was presented in Sup Fig. 1.

\section{Microgravity simulation}

The hucMSCs were seeded in a T-25 flask $\left(1 \times 10^{5}\right.$ cells/flask $)$ and placed in a 96-well plate $\left(2 \times 10^{3}\right.$ cells/well for the cell proliferation assay and $1 \times 10^{3}$ cells $/$ well for the cytoskeleton stains). The T-25 flask and 96-well plate were carefully filled with culture medium (ensuring no bubbles formed to avoid shearing of the fluid) (Leguy et al. 2011). The cell containers were fixed in the sample stage of a clinostat. The clinostat was then placed in a $\mathrm{CO}_{2}$ incubator (Sanyo MCO-18AIC CO ${ }_{2}$ Incubator; Sanyo Electric Co., Japan). The hucMSCs were exposed to SMG using a 3D clinostat $\left(<10^{-3} \mathrm{~g}\right)$ that was operated for $72 \mathrm{~h}$. The control group was treated at $1 \mathrm{~g}$ in the same $\mathrm{CO}_{2}$ incubator.

\section{WST-1 cell proliferation assay}

The hucMSCs were seeded in a 96-well plate (161093; Thermo Fisher Scientific ${ }^{\mathrm{TM}}$ Thermo Scientific) at a concentration of $2 \times 10^{3}$ cells/well and a culture medium of $395 \mu 1 /$ well. Parafilm was used to cover the wells. After the hucMSCs underwent SMG for $72 \mathrm{~h}$, the culture medium was removed and $100 \mu$ of new medium and $10 \mu \mathrm{l}$ WST-1 (11644807001; Roche, Basel, Switzerland) were added to each well. The hucMSCs were incubated for $3.5 \mathrm{~h}$ at $37^{\circ} \mathrm{C}, 5 \% \mathrm{CO}_{2}$ and measured at $450 \mathrm{~nm}$ using a GloMax ${ }^{\circledR}$ Explorer Multimode Microplate Reader (Promega, Madison, WI, USA). A control was treated without the SMG condition.

\section{Flow cytometry analysis}

The hucMSCs were seeded in a T-25 flask (160430; Thermo Fisher Scientific ${ }^{\mathrm{TM}}$ Thermo Scientific) at a concentration of $1 \times 10^{5}$ cells/flask. The flask was filled with culture medium and then capped without causing bubbles in the flask. The hucMSCs were then exposed to SMG for $72 \mathrm{~h}$. Following trypsinization, hucMSCs were fixed with $4 \%$ paraformaldehyde (09154-85; Nacalai Tesque, Kyoto, Japan) for $15 \mathrm{~min}$. 
The hucMSCs were then washed twice with cold PBS and resuspended in $1 \times$ Binding Buffer at a concentration of $1 \times 10^{6}$ cells $/ \mathrm{ml}$. The hucMSCs were then stained with $5 \mu \mathrm{l}$ of propidium iodide (51-66211E; BD Biosciences, San Jose, CA, USA). The cell cycle progression was analyzed by measuring the cellular DNA content using an Accuri C6 plus flow cytometer (BD Biosciences).

\section{Quantitative real-time ( $R T)$ - $P C R$}

Total RNA of the hucMSCs were extracted using the ReliaPrepTM RNA Cell Miniprep System (Z6011; Promega). Each reaction was carried out in a $20 \mu \mathrm{l}$ reaction consisting of $1 \mu \mathrm{l}$ of total RNA, $2 \mu \mathrm{l}$ of primers (forward and reverse), $10 \mu \mathrm{l} 2 \times \mathrm{Mix} \mathrm{Hi}-\mathrm{ROX}$,

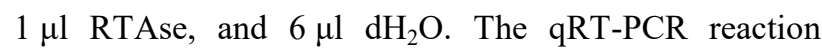
underwent one cycle at $45^{\circ} \mathrm{C}$ for $15 \mathrm{~min}$, one cycle at $95{ }^{\circ} \mathrm{C}$ for $2 \mathrm{~min}, 40$ cycles at $95{ }^{\circ} \mathrm{C}$ for $10 \mathrm{~s}, 60{ }^{\circ} \mathrm{C}$ for $15 \mathrm{~s}$, and 71 cycles at $60^{\circ} \mathrm{C}$ for $15 \mathrm{~s}$. A PikoReal 96 Real-Time PCR System (Thermo Fisher Scientific ${ }^{\mathrm{TM}}$ Thermo Scientific) was used for the qRT-PCR with the $2 \times$ qPCR SyGreen 1-Step Go Hi-ROX kit (PCR Biosystem, London, England). The $2^{-\Delta \Delta \mathrm{Ct}}$ method was used for the $\mathrm{Ct}$ value analysis (Livak and Schmittgen, 2001). Primers were as follows: $\beta$-actin, F 5'-GAG CAC AGA GCC TCG CCT TT-3' and R 5'-AGA GGC GTA CAG GGA TAG CA-3' (Zhao et al. 2015); $\alpha$-tubulin 3, F 5'-CAT TGA AAA GTT GTG GTC TGA TCA-3' and R 5'-GCT TGG GTC TGT AAC AAA GCA T-3' (Fischer et al. 2005), and; glyceraldehyde-3-phosphate dehydrogenase (GAPDH), F 5'-CAT GAG AAG TAT GAC AAC AGC CT-3' and R 5'-AGT CCT TTC CAC GAT ACC AAA GT-3' (Gorgogietas et al. 2018).

\section{Western blot}

The hucMSCs were collected from the T-25 flask and a lysate was prepared using Optiblot LDS sample buffer (ab119196; Abcam). Equal amounts of protein were loaded into the wells of the Precast Gel SDS-PAGE 4-12 \% (ab139596; Abcam). The gel was run in Optiblot SDS Run Buffer (ab119197, Abcam) for $2 \mathrm{~h}$ at $50 \mathrm{~V}$. Protein was transferred to a PVDF membrane (ab133411; Abcam), which was blocked overnight at $4{ }^{\circ} \mathrm{C}$ with a blocking buffer (ab126587; Abcam). The membrane was then incubated with primary antibodies in the blocking buffer overnight at $4{ }^{\circ} \mathrm{C}$. Anti-beta actin antibodies (ab8226; Abcam) and anti-alpha tubulin antibodies (ab52866; Abcam) were used at 1:1000 dilutions. Anti-cyclin A1 + cyclin A2 antibodies (ab185619; Abcam), anti-cyclin-dependent kinase (cdk) 4 antibodies (ab137675; Abcam), and anti-cdk6 antibodies (ab124821; Abcam) were used at 1:5000 dilutions. AntiGAPDH antibodies (ab181602; Abcam) at 1:5000 dilutions were used as a control. The membrane was washed three times for $10 \mathrm{~min}$ each with TBST. The membrane was then incubated with secondary antibodies in a blocking buffer at room temperature for $1 \mathrm{~h}$. Goat anti-mouse IgG (ab6789; Abcam) and goat anti-rabbit IgG (ab6721; Abcam) were used against the beta actin antibodies and other primary antibodies, respectively. The blots were visualized using the ECL Western Blotting Substrate Kit (ab65623; Abcam). Imaging was carried out using X-ray film. The intensities of the protein bands were quantified using ImageJ software (National Institutes of Health, Bethesda, MD, USA).

\section{Microtubule staining}

The hucMSCs were seeded in a 96-well plate at a concentration of $1 \times 10^{3}$ cells/well, with $395 \mu \mathrm{l} /$ well of culture medium. Microtubules were labeled with $2 \mu \mathrm{l}$ SiR-Tubulin (CY-SC002, Cytoskeleton, Inc., Denver, CO, USA) with a final concentration of $50 \mathrm{nM}$ for each well. Parafilm was used to cover the wells. The hucMSCs then underwent SMG for $72 \mathrm{~h}$. The stained hucMSCs were observed using a Cytell microscope (GE Healthcare, Bloomington, IL, USA).

\section{Microfilament staining and nuclear morphology evaluation}

The hucMSCs were seeded in a 96-well plate at a concentration of $1 \times 10^{3}$ cells/well with $395 \mu \mathrm{l} /$ well of culture medium. Parafilm was used to cover the wells. The hucMSCs were placed under the SMG for $72 \mathrm{~h}$. They were then fixed with $4 \%$ paraformaldehyde (Nacalai) for $30 \mathrm{~min}$ and permeabilized with $0.1 \%$ Triton X-100 (Merck, Darmstadt, Germany) overnight at $4{ }^{\circ} \mathrm{C}$. The actin filament was stained using Phalloidin CruzFluor ${ }^{\mathrm{TM}}$ 488 Conjugate (sc-363791; Santa Cruz Biotechnology, Dallas, TX, USA), and the nucleus was stained using Hoechst 33342 (14533; Sigma-Aldrich, St. Louis, MO, USA) for $15 \mathrm{~min}$. The cells were washed three times for $10 \mathrm{~min}$ each with phosphate-buffered saline (Thermo Fisher Scientific ${ }^{\mathrm{TM}}$ Gibco). The stained hucMSCs were observed under a Cytell microscope (GE Healthcare). The cell cycle app of the Cytell microscope was used to assess nuclear morphology, including nuclear area, intensity, and the nuclear-shape value (Son et al. 2019). 


\section{Statistical analysis}

All experiments were performed at least three times. The data were analyzed for statistical significance using one-way ANOVA analyses, where $\mathrm{P}<0.05$ was considered statistically significant.

\section{Results}

\section{Cell proliferation inhibited by $S M G$}

The growth and viability of the hucMSCs was estimated using a WST-1 assay. The absorbance value of the hucMSCs from the SMG group was $0.97 \pm 0.05$, which was lower than the control group $(1.09 \pm 0.13, \mathrm{P}<0.001)$ (Fig. 1A). This result indicates that the proliferation of hucMSCs from the SMG group was lower than the control group.
Flow cytometry analysis was used to assess the cycle progression of hucMSCs. As seen in Figure 1B, the percentage of hucMSCs from the control and SMG groups in the G0/G1 phase were $72.27 \pm 1.28 \%$ and $85.65 \pm 0.65 \%$, respectively $(\mathrm{P}<0.01)$. Furthermore, the total ratio of $\mathrm{S}$ and $\mathrm{G} 2 / \mathrm{M}$ phases of the hucMSCs from the SMG group was lower than the control group $(\mathrm{P}<0.01)$. This suggests that $\mathrm{SMG}$ can induce the cell cycle arrest phase in hucMSCs.

A western blot analysis showed that there was a lower expression of cyclin A1 and A2 proteins in the hucMSCs from the SMG group compared to the control group (Fig 1C). We also observed a downregulation of cdk4 and 6 proteins in the hucMSCs from the SMG group in contrast to the hucMSCs from the control group.
A

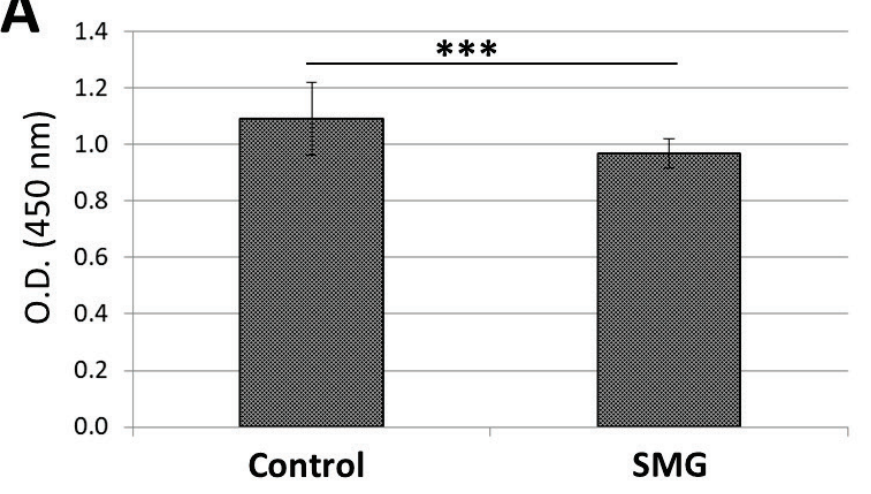

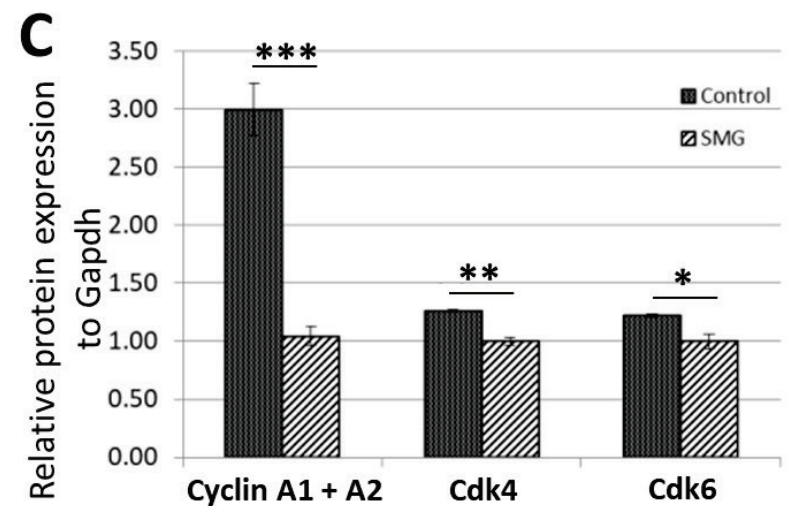

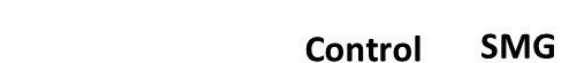

B

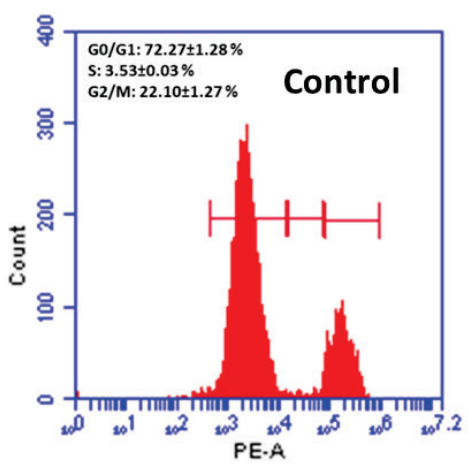



Cyclin $\mathbf{A} 1+\mathbf{A 2}$

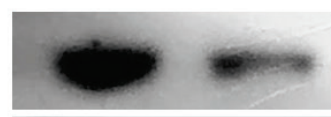

Cdk4

Cdk6

Gapdh

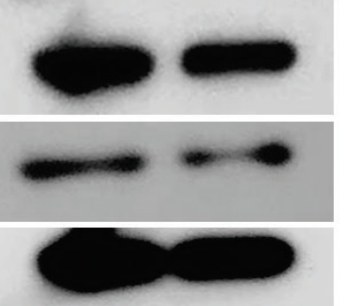

Fig. 1. The proliferation of hucMSCs from control and simulated microgravity (SMG) groups. (A) hucMSC proliferation assessed by a WST-1 kit. In the control group, the OD value of hucMSCs was higher than the SMG group. (B) Flow cytometry analysis of hucMSCs. In the SMG group, hucMSCs showed a higher G0/G1 ratio than the control group, resulting in the induction of cell cycle arrest in the hucMSCs. (C) The expression of major regulators was estimated by western blot. In the SMG group, the expression of cell cycle-related proteins in hucMSCs was downregulated. *** indicates a significant difference compared with the control group $(P<0.001)$. ** indicates a significant difference compared with the control group $(P<0.01) . *$ indicates a significant difference compared with the control group $(P<0.05)$.

\section{Effects of SMG on nuclear morphology}

The intensity of the nucleus was measured using the cell cycle app of the Cytell microscope (Sup. Excel data). The hucMSCs from the SMG group showed a lower total nuclear intensity value than the control group (5629317 \pm 39469 compared to $5957254 \pm 65063$, respectively; $\mathrm{P}<0.001$ ) (Fig. $2 \mathrm{~A}$ ). However, there was no significant difference in the nuclear area between the 
control $\left(318.07 \pm 1.73 \mu \mathrm{m}^{2}\right)$ and the SMG groups (314.04 $\pm 2.55 \mu \mathrm{m}^{2} ; \quad \mathrm{P}=0.197$ ) (Fig. 2B). The nuclearshape value generated by the cell cycle app $(1.0=$ circle, $<1.0=$ non-circular), was also assessed to estimate the nuclear morphology of hucMSCs under SMG (Sup. Excel data). The results demonstrated no significant difference in nuclear shape values between the control $(0.88 \pm 0.003)$ and the SMG groups $(0.89 \pm 0.002 ; \mathrm{P}=0.143)$ (Fig. $2 \mathrm{C})$.

The Figure 2D displays the distribution of the nuclei for both the nuclear-shape value and the total nuclear-intensity value. Figure $2 \mathrm{E}$ shows the distribution of the nuclei for both the nuclear-area value and the total nuclear-intensity value. Nearly all of the nuclei from the SMG group had a distribution lower than $1.00 \mathrm{E}+7$, while the distribution of nuclei from the control group exceeded 1.00E+7. Similar distributions of the nuclear-shape value and nuclear area of the hucMSCs were observed in both the control and SMG groups.

Expression of cytoskeleton-related genes of hucMSCs under $S M G$

In this study, $\beta$-actin and $\alpha$-tubulin expression were analyzed to evaluate the effects of SMG on the hucMSC cytoskeleton. Western blot results revealed the downregulation of both $\beta$-actin and $\alpha$-tubulin in hucMSCs in the SMG group (Fig. 3A). In addition, qRT-PCR analysis revealed a reduction of the $\beta$-actin and $\alpha$-tubulin 3 transcripts in hucMSCs in the SMG group (Fig. 3B).
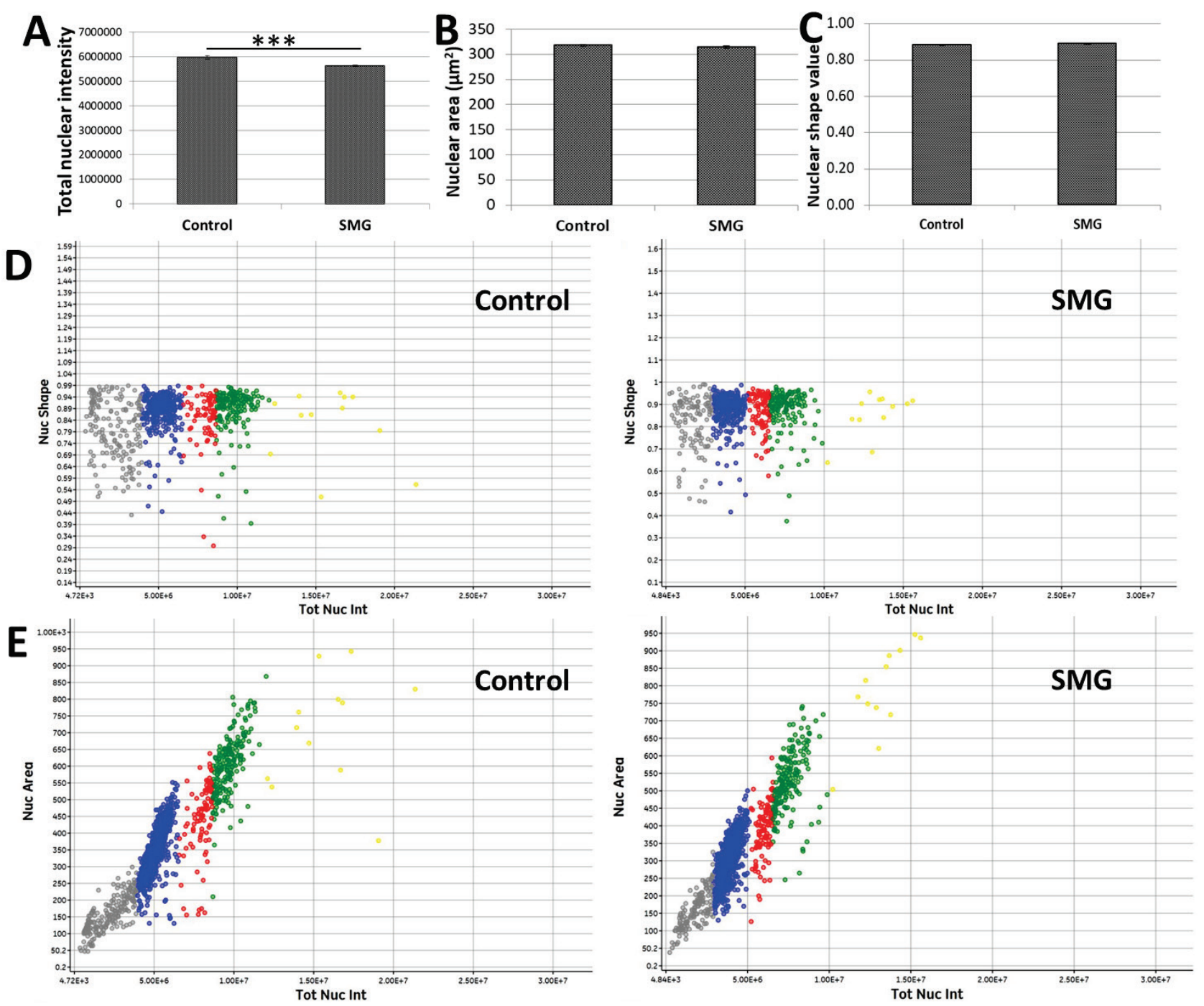

Fig. 2. The evaluation of nuclear morphology in human umbilical cord mesenchymal stem cells (hucMSCs). (A), total nuclear intensity, (B) nuclear area, and (C) nuclear shape of hucMSCs generated by the cell cycle app. In the control group, the nuclei of the hucMSCs showed a higher intensity than those from the simulated microgravity (SMG) group. There was no difference in the nuclear area or nuclear-shape value between the control and SMG groups. (D) The distribution of nuclear-shape values in relation to total nuclear intensity. (E) The distribution of the nuclear area in the relation to total nuclear intensity. Blue color indicates the G0/G1 phase, red indicates the $S$ phase, green indicates the G2/M phase, grey indicates $<2 n$, and yellow indicates $>4 n$. $* * *$ indicates a significant difference compared with the control group $(P<0.001)$. 

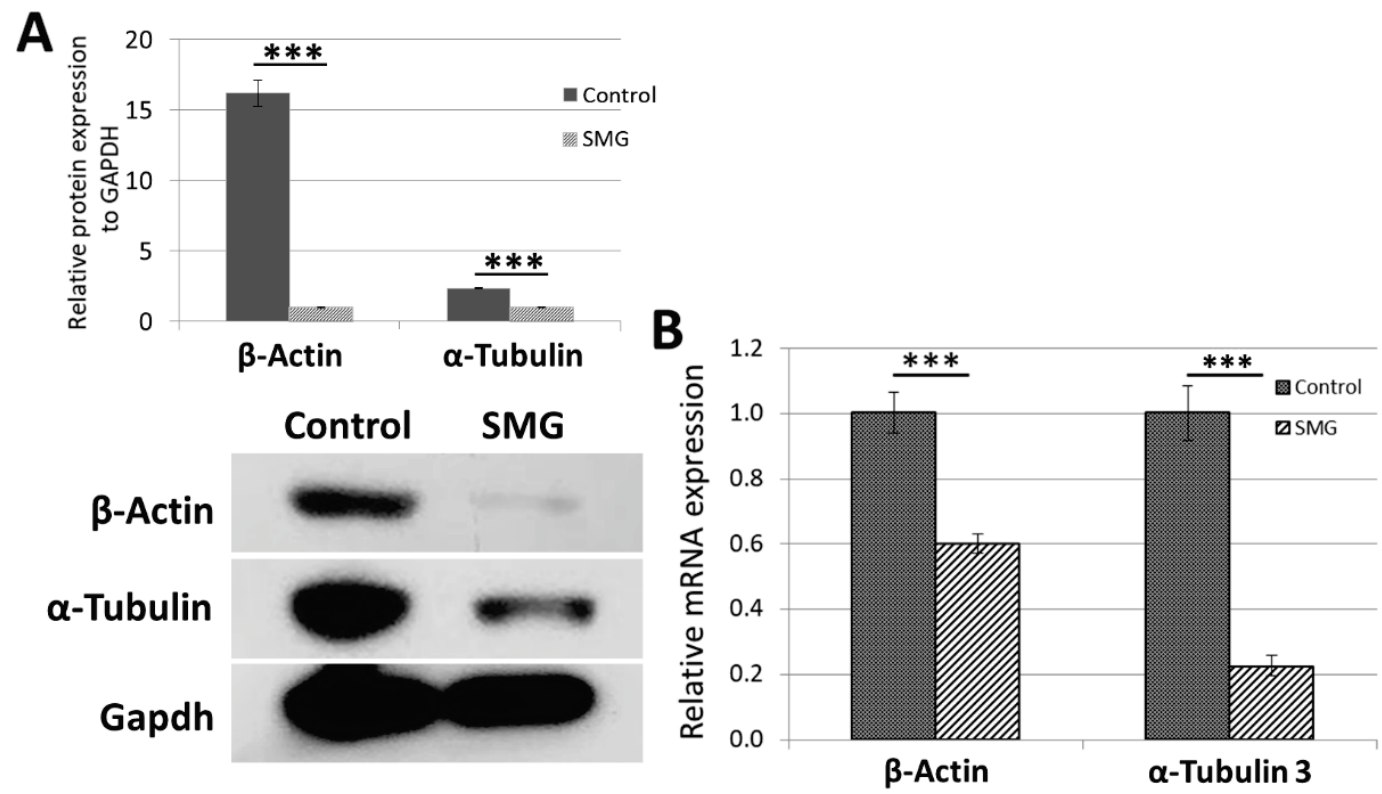

Fig. 3. The expression of $\beta$-actin and a-tubulin in human umbilical cord mesenchymal stem cells (hucMSCs). (A) A western blot analysis shows the expression $\beta$-actin and a-tubulin protein. In the simulated microgravity (SMG) group, hucMSCs demonstrated a lower expression of cytoskeletal proteins than the control group. (B) A qRT-PCR showing the transcript expression of $\beta$-actin and a-tubulin 3 . The $\beta$-actin and a-tubulin 3 transcripts were attenuated in hucMSCs under SMG. *** indicates a significant difference compared with the control group $(\mathrm{P}<0.001)$.

\section{SMG-induced cytoskeleton remodeling in hucMSCs}

We also assessed the morphology of the cytoskeleton by staining the main cytoskeletal proteins. As seen in Figure 4, microtubules were in a parallel distribution and spread throughout the length of the hucMSCs in the control group. This distribution was not observed in the SMG group. Instead, there was a cross distribution of microtubule bundles in the cytoplasm.
Figure 4 also illustrates the parallel distribution of microfilament bundles, which extended throughout the cellular length of the hucMSCs from control group. Both microfilament and microtubule staining revealed the limitations of the length of hucMSCs from the SMG group, where the cells tended to expand out to form a round shape rather than stretch longitudinally.

\section{Control}
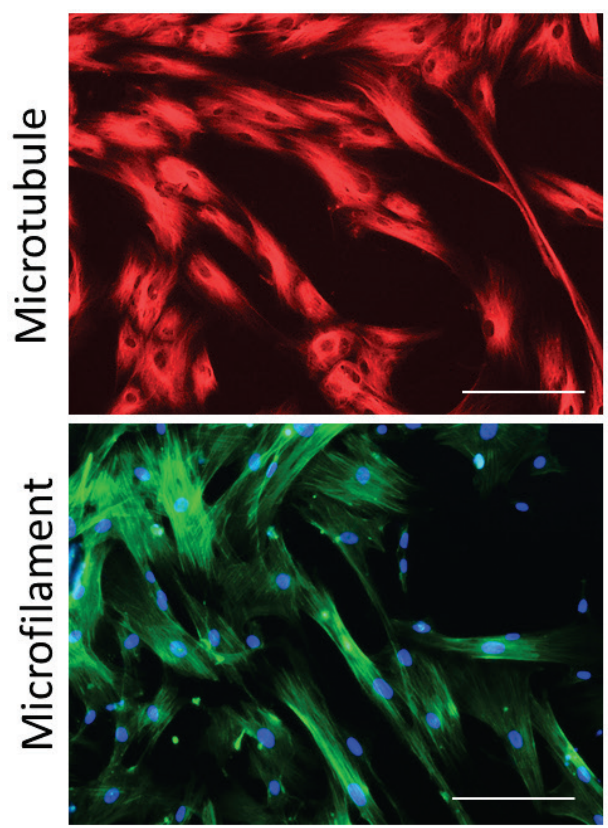

\section{SMG}
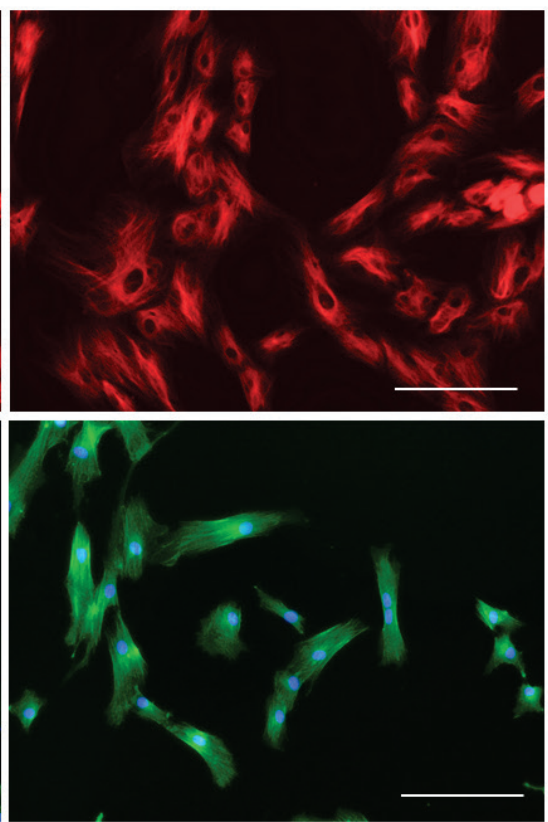

Fig. 4. Cytoskeleton staining of human umbilical cord mesenchymal stem cells. Microtubules were stained with SiR-tubulin (red). Microfilaments were stained with phalloidin (green). The nucleus was counterstained with H33342 (blue). (Magnification $\times 100)$, Scale bar = $200 \mu \mathrm{m}$. 


\section{Discussion}

SMG has been shown to reduce the proliferation of several cell types such as mouse MSCs (Touchstone et al. 2019), mouse skeletal myoblasts (Benavides et al. 2014), human hematopoietic progenitor cells (Plett et al. 2004), melanoma cells (Tan et al. 2018), and bone marrow MSCs (Yan et al. 2015). In this study, we have also shown decreases in hucMSC proliferation under SMG. However, the mechanism underlying the decrease in cell propagation has not been well characterized; although, cell death is not believed to cause this inhibition. Instead, it has been hypothesized that changes in cell cycle progression lead to the inhibition of cell proliferation (Benavides et al. 2014).

In this study, cell cycle progression and the expression of major cell-cycle proteins were shown to be associated with a reduction in hucMSC proliferation. The hucMSCs were arrested in the G0/G1 phase under SMG, suggesting that cell division and proliferation were decelerated. Cell division is the process that enables cell proliferation. In cell cycle progression, cdk4 and cdk6 contribute to the transition from the $\mathrm{G} 1$ to the $\mathrm{S}$ phase (Tigan et al. 2016). This transition plays an important role in controlling cell proliferation (Bertoli et al. 2013), and the inhibition of cdk4/6 causes the attenuation of cell proliferation (Garrido-Castro and Goel 2017, Kollmann et al. 2019, Bonelli et al. 2019). Both cdk4 and cdk6 were downregulated in the hucMSCs under SMG, which resulted in the increased distribution of hucMSCs in the G0/G1 phase.

The downregulation of cyclin A1 and cyclin A2 were also observed in the SMG hucMSCs. Cyclin A1 is crucial for spermatogenesis and is expressed in the testes, while cyclin A2 is expressed throughout the $\mathrm{S}$ and $\mathrm{G} 2$ phases in all proliferating cells ( $\mathrm{Ji}$ et al. 2005, Kalaszczynska et al. 2009). This study demonstrated that the decrease in SMG-induced hucMSC proliferation was accompanied by a decrease in cyclin A1 and A2 expression, which was correlated with a reduction in their total ratio in the $\mathrm{S}$ and $\mathrm{G} 2$ phases. In addition, cell division requires chromatin condensation, which is an important process in mitosis (Habela and Sontheimer 2007). Chromatin condensation was visualized using Hoechst 33342 staining, which increases nuclear intensity (Habela and Sontheimer 2007). The current study illustrates that SMG-induced hucMSCs had a lower nuclear intensity than the control group. This result indicates that there was a decrease in chromatin condensation, leading to a decrease in SMG hucMSC division.

The cytoskeleton is a structure that maintains cellular shape and organization, as well as providing support for cell division and movement. The two main components of the cytoskeleton are actin and tubulin, which form microfilaments and microtubules, respectively (Nakaseko and Yanagida 2001). In this investigation, a reorganization of the microtubules and microfilaments were observed in hucMSCs from the SMG group. The remodeling of microtubules in SMG-induced hucMSCs were distributed with equivalent density throughout the entire body cell. In contrast, the microtubules of the hucMSCs from the control group displayed a higher density around the nucleus. The remodeling of the microfilaments was also observed in the SMG-exposed hucMSCs. The remodeling of microfilaments of SMG-exposed MSCs and microtubules of chondrocytes has also been characterized in previous studies (Chen et al. 2016, Cazzaniga et al. 2016, Aleshcheva et al. 2013). However, the relationship between the remodeling of microtubules and microfilaments and the levels of actin and tubulin expression has not been characterized. The present study shows that the decrease of $\alpha$-tubulin and $\beta$-actin expression results in the remodeling of microtubules and microfilaments in SMG-exposed hucMSCs.

In conclusion, our results show there is a downregulation of major cell cycle proteins and cytoskeletal proteins in SMG exposed hucMSCs. This suggests that SMG inhibits proliferation of hucMSCs by promoting cell cycle arrest.

\section{Conflict of Interest}

There is no conflict of interest.

\section{Acknowledgements}

This work was supported by Project VT-CB.15/18-20 of the Space Science and Technology Program from the Vietnam Academy of Science and Technology.

\section{Abbreviations}

CDKs - Cyclin-dependent kinases, GAPDH Glyceraldehyde-3-phosphate dehydrogenase, hucMSCs Human umbilical cord mesenchymal stem cells, IGF-1 Insulin-like growth factor 1, MSCs - Mesenchymal stem cells, PI - Propidium iodide, SMG - Simulated microgravity, TRPC1 - Transient receptor potential canonical type 1 . 


\section{References}

ALESHCHEVA G, SAHANA J, MA X, HAUSLAGE J, HEMMERSBACH R, EGLI M, INFANGER M, BAUER J, GRIMM D: Changes in morphology, gene expression and protein content in chondrocytes cultured on a random positioning machine. PLoS One 8: e79057, 2013. https://doi.org/10.1371/journal.pone.0079057

BENAVIDES DAMM T, RICHARD S, TANNER S, WYSS F, EGLI M, FRANCO-OBREGON A: Calciumdependent deceleration of the cell cycle in muscle cells by simulated microgravity. FASEB J 27: 2045-2054, 2013. https://doi.org/10.1096/fj.12-218693

BENAVIDES DAMM T, WALTHER I, WÜEST SL, SEKLER J, EGLI M: Cell cultivation under different gravitational loads using a novel random positioning incubator. Biotechnol Bioeng 111: 1180-1190, 2014. https://doi.org/10.1002/bit.25179

BERTOLI C, SKOTHEIM JM, DE BRUIN RA: Control of cell cycle transcription during G1 and S phases. Nat Rev Mol Cell Biol 14: 518-528, 2013. https://doi.org/10.1038/nrm3629

BONELLI M, LA MONICA S, FUMAROLA C, ALFIERI R: Multiple effects of CDK4/6 inhibition in cancer: From cell cycle arrest to immunomodulation. Biochem Pharmacol 170: 113676, 2019. https://doi.org/10.1016/j.bcp.2019.113676

CAZZANIGA A, MAIER JAM, CASTIGLIONI S: Impact of simulated microgravity on human bone stem cells: New hints for space medicine. Biochem Biophys Res Commun 473: 181-186, 2016. https://doi.org/10.1016/j.bbrc.2016.03.075

CHEN Z, LUO Q, LIN C, KUANG D, SONG G: Simulated microgravity inhibits osteogenic differentiation of mesenchymal stem cells via depolymerizing F-actin to impede TAZ nuclear translocation. Sci Rep 6: 30322 , 2016. https://doi.org/10.1038/srep30322

CRUCIANI S, GARRONI G, VENTURA C, DANANI A, NEČAS A, MAIOLI M: Stem cells and physical energies: can we really drive stem cell fate? Physiol Res 68 (Suppl 4): S375-S384, 2019. https://doi.org/10.33549/physiolres.934388

DEVARASETTY M, WANG E, SOKER S, SKARDAL A: Mesenchymal stem cells support growth and organization of host-liver colorectal-tumor organoids and possibly resistance to chemotherapy. Biofabrication 9: 021002, 2017. https://doi.org/10.1088/1758-5090/aa7484

DOAN CC, LE TL, HOANG NS, DOAN NT, LE VD, DO MS: Differentiation of umbilical cord lining membranederived mesenchymal stem cells into endothelial-like cells. Iran Biomed J 18: 67-75, 2014. https://doi.org/10.1155/2013/749587

DOAN CC, LE TL, HOANG NS, NGUYEN DK, NGUYEN HC, LE VD, DO MS: Differentiation of human umbilical cord lining membrane-derived mesenchymal stem cells into hepatocyte-like cells. Int Sch Res Notices 2013: 749587, 2013. https://doi.org/10.1155/2013/749587

FISCHER M, SKOWRON M, BERTHOLD F: Reliable transcript quantification by real-time reverse transcriptasepolymerase chain reaction in primary neuroblastoma using normalization to averaged expression levels of the control genes HPRT1 and SDHA. J Mol Diagn 7: 89-96, 2005. https://doi.org/10.1016/s1525-1578(10)60013-X

GARRIDO-CASTRO AC, GOEL S: CDK4/6 Inhibition in breast cancer: mechanisms of response and treatment failure. Curr Breast Cancer Rep 9: 26-33, 2017. https://doi.org/10.1007/s12609-017-0232-0

GORGOGIETAS VA, TSIALTAS I, SOTIRIOU N, LASCHOU VC, KARRA AG, LEONIDAS DD, CHROUSOS GP, PROTOPAPA E, PSARRA AG: Potential interference of aluminum chlorohydrate with estrogen receptor signaling in breast cancer cells. J Mol Biochem 7: 1-13, 2018.

GRIFFONI C, Di MOLFETTA S, FANTOZZI L, ZANETTI C, PIPPIA P, TOMASI V, SPISNI E: Modification of proteins secreted by endothelial cells during modeled low gravity exposure. J Cell Biochem 112: 265-272, 2011. https://doi.org/10.1002/jcb.22921

HABELA CW, SONTHEIMER H: Cytoplasmic volume condensation is an integral part of mitosis. Cell Cycle 6: 1613-1620, 2007. https://doi.org/10.4161/cc.6.13.4357

HUANG Y, DAI ZQ, LING SK, ZHANG HY, WAN YM, LI YH: Gravity, a regulation factor in the differentiation of rat bone marrow mesenchymal stem cells. J Biomed Sci 16: 87, 2009. https://doi.org/10.1186/1423-0127-16-87 
IMURA T, OTSUKA T, KAWAHARA Y, YUGE L: "Microgravity" as a unique and useful stem cell culture environment for cell-based therapy. Regen Ther 12: 2-5, 2019. https://doi.org/10.1016/j.reth.2019.03.001

JI P, AGRAWAL S, DIEDERICHS S, BÄUMER N, BECKER A, CAUVET T, KOWSKI S, BEGER C, WELTE K, BERDEL WE, SERVE H, MÜLLER-TIDOW C: Cyclin A1, the alternative A-type cyclin, contributes to G1/S cell cycle progression in somatic cells. Oncogene 24: 2739-2744, 2005. https://doi.org/10.1038/sj.onc.1208356

KALASZCZYNSKA I, GENG Y, IINO T, MIZUNO S, CHOI Y, KONDRATIUK I, SILVER DP, WOLGEMUTH DJ, AKASHI K, SICINSKI P: Cyclin A is redundant in fibroblasts but essential in hematopoietic and embryonic stem cells. Cell 138: 352-365, 2009. https://doi.org/10.1016/j.cell.2009.04.062

KLADNICKÁ I, ČEDÍKOVÁ M, KRIPNEROVÁ M, DVOŘÁKOVÁ J, KOHOUTOVÁ M, TƯMA Z, MÜLLEROVÁ D, KUNCOVÁ J: Mitochondrial respiration of adipocytes differentiating from human mesenchymal stem cells derived from adipose tissue. Physiol Res 68 (Suppl 3): S287-S296, 2019. https://doi.org/10.33549/physiolres. 934353

KOLLMANN K, BRIAND C, BELLUTTI F, SCHICHER N, BLUNDER S, ZOJER M, HOELLER C: The interplay of CDK4 and CDK6 in melanoma. Oncotarget 10: 1346-1359, 2019. https://doi.org/10.18632/oncotarget.26515

LEGUY CAD, DELFOS R, POURQUIE MJBM, POELMA C, KROONEMAN J, WESTERWEEL J, VAN LOON JJWA: Fluid motion for micro-gravity simulations in a random positioning machine. Gravit Space Biol 25: 36-39, 2011.

LIVAK KJ, SCHMITTGEN TD: Analysis of relative gene expression data using Real-Time Quantitative PCR and the 2- $\Delta \Delta \mathrm{Ct}$ method. Methods 25: 402-408, 2001. https://doi.org/10.1006/meth.2001.1262

MAO X, CHEN Z, LUO Q, ZHANG B, SONG G: Simulated microgravity inhibits the migration of mesenchymal stem cells by remodeling actin cytoskeleton and increasing cell stiffness. Cytotechnology 68: 2235-2243, 2016. https://doi.org/10.1007/s10616-016-0007-x

MARINO L, CASTALDI MA, ROSAMILIO R, RAGNI E, VITOLO R, FULGIONE C, CASTALDI SG, SERIO B, BIANCO R, GUIDA M, SELLERI C: Mesenchymal stem cells from the Wharton's jelly of the human umbilical cord: biological properties and therapeutic potential. Int J Stem Cells 12: 218-226, 2019. https://doi.org/10.15283/ijsc18034

NAKASEKO Y, YANAGIDA M: Cytoskeleton in the cell cycle. Nature 412: 291-292, 2001. https://doi.org/10.1038/35085684

PLETT PA, ABONOUR R, FRANKOVITZ SM, ORSCHELL CM: Impact of modeled microgravity on migration, differentiation, and cell cycle control of primitive human hematopoietic progenitor cells. Exp Hematol 32: 773-781, 2004. https://doi.org/10.1016/j.exphem.2004.03.014

REA G, CRISTOFARO F, PANI G, PASCUCCI B, GHUGE SA, CORSETTO PA, IMBRIANI M, VISAI L, RIZZO AM: Microgravity-driven remodeling of the proteome reveals insights into molecular mechanisms and signal networks involved in response to the space flight environment. J Proteomics 137: 3-18, 2016. https://doi.org/10.1016/j.jprot.2015.11.005

SAMBANDAM Y, TOWNSEND MT, PIERCE JJ, LIPMAN CM, HAQUE A, BATEMAN TA, REDDY SV: Microgravity control of autophagy modulates osteoclastogenesis. Bone 61: 125-131, 2014. https://doi.org/10.1016/j.bone.2014.01.004

SON HN, CHI HNQ, CHUNG DC, LONG LT: Morphological changes during replicative senescence in bovine ovarian granulosa cells. Cell Cycle 18: 1490-1497, 2019. https://doi.org/10.1080/15384101.2019.1624108

TAN X, XU A, ZHAO T, ZHAO Q, ZHANG J, FAN C, DENG Y, FREYWALD A, GENTH H, XIANG J: Simulated microgravity inhibits cell focal adhesions leading to reduced melanoma cell proliferation and metastasis via FAK/RhoA-regulated mTORC1 and AMPK pathways. Sci Rep 8: 3769, 2018. https://doi.org/10.1038/s41598018-20459-1

TIGAN AS, BELLUTTI F, KOLLMANN K, TEBB G, SEXL V: CDK6-a review of the past and a glimpse into the future: from cell-cycle control to transcriptional regulation. Oncogene 35: 3083-3091, 2016. https://doi.org/10.1038/onc.2015.407

TOUCHSTONE H, BRYD R, LOISATE S, THOMPSON M, KIM S, PURANAM K, SENTHILNATHAN AN, PU X, BEARD R, RUBIN J, ALWOOD J, OXFORD JT, UZER G: Recovery of stem cell proliferation by low intensity vibration under simulated microgravity requires LINC complex. NPJ Microgravity 5: 11, 2019. https://doi.org/10.1038/s41526-019-0072-5 
TRÁVNÍČKOVÁ M, BAČÁKOVÁ L: Application of adult mesenchymal stem cells in bone and vascular tissue engineering. Physiol Res 67: 831-850, 2018. https://doi.org/10.33549/physiolres.933820

WANG C, CHEN H, LUO H, ZHU L, ZHAO Y, TIAN H, WANG R, SHANG P, ZHAO Y: Microgravity activates p38 MAPK-C/EBPbeta pathway to regulate the expression of arginase and inflammatory cytokines in macrophages. Inflamm Res 64: 303-311, 2015. https://doi.org/10.1007/s00011-015-0811-3

WEISS ML, TROYER DL: Stem cells in the umbilical cord. Stem Cell Rev 2: 155-162, 2006. https://doi.org/10.1007/s12015-006-0022-y

YAN M, WANG Y, YANG M, LIU Y, QU B, YE Z, LIANG W, SUN X, LUO Z: The effects and mechanisms of clinorotation on proliferation and differentiation in bone marrow mesenchymal stem cells. Biochem Biophys Res Commun 460: 327-332, 2015. https://doi.org/10.1016/j.bbrc.2015.03.034

ZHAO J, FU W, LIAO H, DAI L, JIANG Z, PAN Y, HUANG H, MO Y, LI S, YANG G, YIN J: The regulatory and predictive functions of miR-17 and miR-92 families on cisplatin resistance of non-small cell lung cancer. BMC Cancer 15: 731, 2015. https://doi.org/10.1186/s12885-015-1713-z 